\title{
Does Soybean (Glycine max) Supplementation Increase Oocyte Viability, Decrease Oocyte Apoptosis and Improve Embryo Development Quality? An Experimental Study
}

\author{
Silvia W Lestari ${ }^{1}$, , Khairunnisa F llato ${ }^{2}$, M. Iqbal A Pratama², Husna Qonitah³, Gito Wasian', Amandanu \\ Bramantya ${ }^{2}$, Firda A Husna ${ }^{4}$, Ria Margiana ${ }^{5}$, Gita Pratama ${ }^{6}$
}

\begin{abstract}
Silvia W Lestari ${ }^{1 * *}$, Khairunnisa F llato ${ }^{2}$, M. Iqbal A Pratama ${ }^{2}$, Husna Qonitah ${ }^{3}$, Gito Wasian' ${ }^{1}$, Amandanu Bramantya ${ }^{2}$, Firda A Husna ${ }^{4}$, Ria Margiana $^{5}$, Gita Pratama ${ }^{6}$
\end{abstract}

'Department of Medical Biology, Faculty of Medicine, Universitas Indonesia, Jakarta, INDONESIA.

'Undergraduate Study of Medicine of Faculty Medicine, Universitas INDONESIA.

3Undergraduate Study of Biology of

Faculty Mathematics and Natural Science, Universitas INDONESIA.

${ }^{4}$ Master's programme in biomedical medicine of Faculty Medicine, Universitas INDONESIA.

${ }^{5}$ Department of Anatomy, Faculty of

Medicine, Universitas Indonesia, Jakarta, INDONESIA.

${ }^{6}$ Department of Obstetry \& Gynecology, Faculty of Medicine, Universitas Indonesia - Ciptomangunkusumo Hospital, Jakarta, INDONESIA.

\section{Correspondence}

\section{Silvia W Lestar}

Department of Medical Biology, Faculty of Medicine, Universitas Indonesia, Jakarta, INDONESIA

E-mail: finallysilvia@gmail.com

History

- Submission Date: 08-12-2021;

- Review completed: 08-01-2022;

- Accepted Date: 17-01-2022.

DOI : 10.5530/pj.2022.14.18

Article Available online http://www.phcogj.com/v14/i1

\section{Copyright}

(C) 2022 Phcogj.Com. This is an openaccess article distributed under the terms of the Creative Commons Attribution 4.0 International license.

\begin{abstract}
Introduction: One of the important factors in Assisted Reproductive Technology (ART) is embryo quality that depends on oocyte quality. Maternal nutrition in form of soybean supplementation is thought to have benefits in oocyte quality. To determine the effect soybean supplementation to the embryo quality from oocyte side. Methods: This experimental study involved female mice from Swiss strain aged 6 weeks that were divided into two groups, group with soybean (soybean group/SG) and group without soybeans (pellet group/PG). Follicles were collected and denuded to get oocytes. The oocytes were stained with MitoTracker for assessing the mitochondrial membrane potential and TUNEL for assessing the apoptotic level. Colour intensity was assessed using a confocal microscope and determined using ImageJ software. Sperms were extracted surgically from the epididymis-vas deferens and performed preparation prior to intra cytoplasmic sperm injection (ICSI) procedure. Then, the embryos were cultured and observed for the quality. Result: In TUNEL test, the average colour intensity of the SG was lower compared to the PG, significantly $(p=0.03)$. While in the Mito Tracker test, the average colour intensity for the SG was higher compared to $P G$, not significantly $(p=1.08)$. In addition, the embryo development on Day-1 and Day-3 showed more good embryo quality of $S G$ compared to $P G$, significantly $(p=0.03)$. Conclusion: Soybean supplementation improved embryo quality at the cleavage stage by decreasing apoptosis of the oocytes rather than increasing the viability the oocytes.
\end{abstract}

Key words: Oocyte, Soybean, Apoptosis, Embryo development, Embryo quality.

\section{INTRODUCTION}

Infertility, defined by the WHO as the inability to conceive after 12 months of regular, unprotected sex, is a global problem on the rise. ${ }^{1}$ One of the main treatment used is through assisted reproductive technologies (ART) such as conventional in vitro fertilization (IVF) - intra cytoplasmic sperm injection (ICSI), whose success rates are often still disappointingly low. ${ }^{2}$ In order to increase the success rates, factors influencing the quality of embryo need to be explored further. One important factor influencing is the oocyte, especially in terms of nutrient consumption. ${ }^{3}$ There are various nutrients which may affect oocyte quality. Polyunsaturated fatty acids (PUFA) such as linoleic acid are known to exert positive effect on oocytes through their influence on membrane composition and cellular signalling, but other researches show that PUFAs inhibit oocyte and embryonal growth in human and bovine oocytes. ${ }^{4-7}$ Other nutrient of interest is the isoflavone genistein. In experiments using mice oocyte, genistein is known to inhibit maturity, but in yet another research also using mice oocyte, it is known that genistein increase post-cryopreservation survivability. ${ }^{8,9}$ These conflicting results demands further research on the supplementation of both nutrients, which are both found in soybeans (Glycine max).

Unfortunately, although containing these nutrients, researches on the effect of soybean supplementation towards oocyte quality in the molecular level are lacking. One way to measure the viability of oocytes are by assessing the mitochondria. A viable mitochondria should be able to maintain a membrane potential between -136 to $-140 \mathrm{mV} \cdot{ }^{10}$ This membrane potential is the ideal range for ATP production. One way to measure this membrane potential is through the use of dyes reactive to the membrane potential such as the MitoTracker, which would be concentrated on active mitochondria. MitoTracker is a preferable dye for measurement since its reactivity with thiol groups in the mitochondrion let the dye stay after the cell dies. ${ }^{11,12}$ Another way to determine oocyte viability is to assess the level of apoptosis in oocytes by using Terminal Deoxyuridine Triphospates Nick-End Labeling (TUNEL). TUNEL serves as a marker of DNA fragment on oocytes, thus provides information about the fragmentation of DNA that occur in advanced apoptosis. However, as DNA fragmentation can occur in both state of cell apoptosis and necrosis, TUNEL is not a specific reagent to determine apoptosis but it can adequately describe the condition of DNA at any given moment. ${ }^{13}$

The hope is that with qualified oocytes, especially in terms of viability and apoptosis, it can produce more qualified embryos too. This study was aimed to determine the oocyte viability, apoptosis and embryo development quality due to the soybean supplementation for nutrition. Thus, embryonal development is another parameter which could be measured. One of the methods used in assessing embryonal development is the modified Gardner 
scoring system which observed morphological criteria during the development of embryos over time. ${ }^{14}$

\section{MATERIALS AND METHODS}

\section{Ethical considerations}

The study protocol and ethical permit for this study was approved by the ethics committee of the Faculty of Medicine, Universitas Indonesia with ethics certificate number KET-1031/UN2.F1/ETIK/ PPM.00.02/2019.

\section{Subjects}

The sample in this study were female and male mice (Mus musculus) of the Swiss strain (age of $8-10$ and $12-15$ weeks, respectively). All mice were purchased from Animal Research Facilities - Institute of Medical Education and Research in Indonesia (ARF-IMERI) (Jakarta, Indonesia) and maintained under conditions of $22 \pm 2{ }^{\circ} \mathrm{C}$ temperature and $12 \mathrm{~h} / 12 \mathrm{~h}$ dark/light cycle, with free access to food and water. In this study, the female mice were divided into two groups: untreated (pellet group/PG) and treated (soybean group/SG). Based on Federer, it was decided that the number of mice for each group was 30 so that the total number of female mice in this study was 60 mice. All mice were randomly allocated in two groups. Besides that, a double-blind method was also used to minimize the bias potential. Initially, 60 female and 24 male mice (Mus musculus) of the Swiss strain were selected. Of these, 10 female mice were excluded due to lack of response to ovarian stimulation and 6 male mice were also excluded due to failure of sperm retrieval from the epididymis. Finally, 50 female mice was divided into two groups (soybean group/SG and pellet group/PG). Observation of the life of mice in the cage was observed every day, whether they were healthy or sick.

\section{Study setting}

This experimental study was conducted to evaluate the viability and apoptosis of oocyte and quality of the embryo development, with soybean supplementation. The samples was took place at Animal Research Facilities (ARF) and Human Reproduction, Infertility and Family Planning (HRIFP), Indonesian Medical Education and Research Institute (IMERI) - Medical Biology Department, Faculty of Medicine, Universitas Indonesia, between January - December 2020.

\section{Soybean supplementation}

One group of 30 female mice were fed by soybeans in the form of uncooked seeds, mixed with standard commercial pellet (Indofeed, Indonesia Formula Feed, Indonesia) (soybean group/SG) while the other group of 30 female mice were fed by pellets only (pellet group/ PG). The amount of soybeans was referred to the Nutrient Requirements of Laboratory Animals, $4^{\text {th }}$ revision, by the National Research Council. According to the guideline, it requires $120 \mathrm{~g}$ of soybean seed per kilogram body weight of mice. In this research, the dose for 5 mice was calculated and given in one feeding bowl for each cage.

\section{Oocyte source}

Hormonal stimulation was performed to increase follicular development using $10 \mathrm{IU}$ of the FSH analog (Gonal-F, Merck, Denmark). Sixteen hours before oocyte collection, ovulation was triggered using $10 \mathrm{IU}$ of the LH analog (Ovidrel, Merck, Denmark) injected intraperitoneally. Euthanasia with cervical dislocation was performed prior surgical removal of ovaries and fallopian tubes. The separation of oocyte from the surrounding cumulus cells were done by denuding process using hyaluronidase enzyme (Hyase, Vitrolife, Sweden). Of 60 female mice, around 120 oocytes were obtained in SG while 80 oocytes were obtained in PG.

\section{Oocyte vitality through mitochondrial membrane potential assessment using MitoTracker}

The MitoTracker solution at a concentration of $25 \mathrm{nM}$ was prepared for staining according to the manufacturer's instructions. Oocyte was first be incubated in a MitoTracker Red CMXRos (Thermo Fisher Scientific, USA) droplet covered by liquid paraffin for $30 \mathrm{~min}$ in an incubator $\left(37^{\circ} \mathrm{C}\right.$ and $\left.6 \% \mathrm{CO}_{2}\right)$. After washing 3 times, each for $10 \mathrm{~min}$ at $37^{\circ} \mathrm{C}$ in phosphate-buffered saline (PBS), the oocyte were fixed in paraformaldehyde on a slide for 30 minutes at room temperature under dark conditions. After washing 3 times, the oocyte were mounted on glass slides and observed under confocal laser microscope (Zeiss) which would use $550 \mathrm{~nm}$ filter to obtain the fluorescence of the dye. Colour intensity was assessed using Image J software. Intensity data from the 2 groups were compared using independent $t$-test in SPSS with significant $\mathrm{p}$ value $<0.05$.

\section{Oocytes apoptotic level assessment using TUNEL}

Each oocyte was fixed in $4 \%$ paraformaldehyde (PFA) in PBS at room temperature for 1 hour. The oocytes were then washed 3 times for 10 minutes in PBS $3 \mathrm{mg} / \mathrm{mL}$ polyvinylpyrrolidone (PBS-PVP). Furthermore, oocytes were stabilized into Triton X-100 0.1\% (wt/ vol) containing $0.1 \%(\mathrm{wt} / \mathrm{vol})$ sodium citrate in PBS. Permeabilization was carried out for 30 minutes at $4^{\circ} \mathrm{C}$. After permeabilization, oocytes were washed again 3 times for 10 minutes in PBS-PVP. The oocytes were then incubated for 1 hour at $37^{\circ} \mathrm{C}$ under dark condition in a 50 $\mu \mathrm{L}$ TUNEL reaction mixture (containing TdT and FITC-dUTP) (in situ Cell Death Detection Kit, Roche, Indianapolis). After incubation, oocytes were washed in PBS and $50 \mu \mathrm{L}$ of Propidium Iodine (PI) was added. The oocyte was again washed in PBS then framed using a cover glass. Apoptotic status assessment was carried out using a confocal laser microscope (Zeiss) by 20x10 magnification. Green fluorescence was observed using a fluorescent isothiocyanate (FITC) filter and a 4,6-diamidine-2-phenylindole (DAPI) filter. The intensity would be analyzed using ImageJ software. Intensity data from the 2 groups were compared using independent $t$-test in SPSS with significant $\mathrm{p}$ value $<0.05$.

\section{Sperm source and preparation}

Sperm for the fertilization was extracted through surgical removal of the epididymis and vas deferens from male mice. The sperm was then prepared through the swim up technique of the sperm preparation to obtain motile sperms. (Sperm Rinse, Vitrolife, Sweden) An aliquot of sperm dilution from epididymis-vas deferens and $1 \mathrm{ml}$ of Sperm Rinse medium were placed in a tube and centrifuged at $300 \mathrm{~g}$ for $10 \mathrm{~min}$. The supernatant was discarded and the pellet was resuspended by $1 \mathrm{ml}$ of Sperm Rinse medium. Furthermore, the tube was placed in $45^{\circ}$ at $37^{\circ} \mathrm{C}$ for $45 \mathrm{~min}$. Then, the upper layer was aspirated and further used.

\section{Intracytoplasmic sperm injection (ICSI)}

The oocyte was placed in a GMOPS drops (Vitrolife, Sweden) and then covered by liquid paraffin. Prior to ICSI, the sperm was immobilized by touching the tail with injection pipette in polyvinylpyrrolidone/PVP (Vitrolife, Sweden) drop in ICSI dish. During ICSI, a selected sperm was then extracted using an injection pipette. Then, the oocyte was held in 3 o'clock position using a holding pipette and the sperm be injected into the ooplasm. The oocyte was transferred to the G1 medium (Vitrolife, Sweden) to be incubated inside a triple-gas incubator $\left(5 \% \mathrm{O}_{2}, 6 \% \mathrm{CO}_{2}\right.$, and $5 \% \mathrm{~N}_{2}$ ) with a temperature of $37^{\circ} \mathrm{C}$. After embryonal cleavage had entered the 6-8 cell stage, the embryo would be transferred to the G2 medium (Vitrolife, Sweden).

\section{Embryo development quality}

Embryonal growth was observed from time to time using an inverted microscope. Embryo development quality was assed using the grading 
system used by the modification of Gardner. ${ }^{14}$ This grading system assessed the cleavage of embryo by the number of cells/blastomeres, similarity of blastomere size and the existence of fragmentation, into 3 categories, namely A. Good, B. Moderate and C. Poor (15). For the number of blastomeres : category A. Good: 2 cells (day-1), 7-9 cells (day-3); B. Moderate: 1 cell (day-1), 6 cells (day-3); C. Poor: 0 cells (day-1), $<6$ cells (day-3), while in the similarity of blastomeres size (category A. Good: all blastomeres are in equal size; B. Moderate: $<50 \%$ of blastomeres are in unequal size; C. Poor : $>50 \%$ of blastomeres are in unequal size) and for the existence of fragmentation (category A. Good : $<10 \%$ of fragmentation; B. Moderate: $10-25 \%$ of fragmentation; C. Poor : $>25 \%$ of fragmentation). ${ }^{15}$ In this study, this grading was simplified into 2 categories, where category A and B were combined into good and C was still in the poor categories, namely : 1 . good and 2 . poor categories. Of 120 oocytes, 96 embryos were obtained in SG while 65 oocytes were obtained in PG.

\section{Statistical analysis}

SPSS Statistics version $22^{\text {nd }}$ program was used to performed the statistical analysis. The data of each research parameter were analyzed between the two groups. Independent t-tests were used to analyze oocyte viability and apoptosis parameters, while Mann-Whitney test was used to analysis embryo development. The significance level was set at $5 \%(\mathrm{p} \leq 0.05)$.

\section{RESULTS AND DISCUSSION}

\section{Oocyte viability}

The viable oocytes among the 2 groups could be seen in Figure 1, by the pattern of mitochondrial distribution, presented by the colour intensity (Figure $1 \mathrm{~A}$ and $1 \mathrm{~B}$ ). Figure 1 showed that the oocyte intensity of SG Figure 1A) is hinger compared to the PG (Figure 1B). Moreover, the average colour intensity of the SG $(2,715 \pm 0,3)$ was higher than the PG $(1,903 \pm 0,1)$ as displayed in Figure 1C. Although higher, the difference was determined not to be statistically significant. $(p=1.08)$ The statistical test used for oocyte viability was the independent t-test.

\section{Oocyte apoptosis}

The apoptotic oocytes among the 2 groups could be seen in Figure 2, presented by the intensity (Figure 2). Figure 2 showed that the oocyte intensity of SG (Figure 2A) is lower compared to the PG (Figure 2B). The mean of these two groups had a significant difference $(\mathrm{p}=0.03)$ with the intensity value of the $S G$ at $0.89 \pm 0.15$ and $P G$ at $2.57 \pm 0.67$ (Figure $2 \mathrm{C}$ ). The statistical test used for oocyte apoptosis was the independent t-test.

\section{Embryo development quality}

Results of embryo development were presented as Day-1 and Day-3 embryos. The Day-1 embryo consisting of 2 cells or less, with an equal and unequal size, with and no fragmentation, resulting in the good and poor qualities of embryo (Figure $3 \mathrm{~A}$ and $3 \mathrm{~B}$ ). The Day- 3 embryo consisting of 6-8 cells or less, with an equal and unequal size, with and no fragmentation, resulting in the good and poor qualities of embryo (Figure 3C and 3D).

In addition, Figure 4 showed the results of embryo development of Day-1 and Day-3 in SG and PG. On Day-1, SG showed more good quality embryos compared to PG, while Day-3 showed similar result to Day-1 that SG showed more good quality embryos compared to PG, significantly ( $\mathrm{p}=0.03$ ) (Figure 4$)$. The statistical test used for embryo development was the Mann-Whitney test.
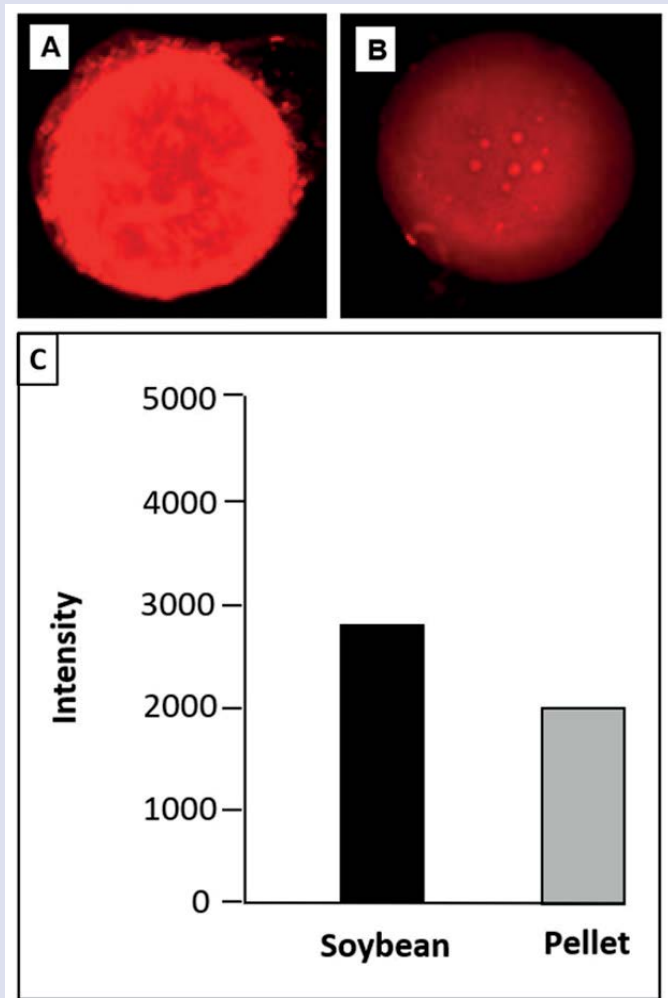

Figure 1: Oocytes viability at (A) soybean-fed group, (B) pellet-only group, (C) intensity of oocyte viability in both groups (dark colour = soybean group and grey colour = pellet group).
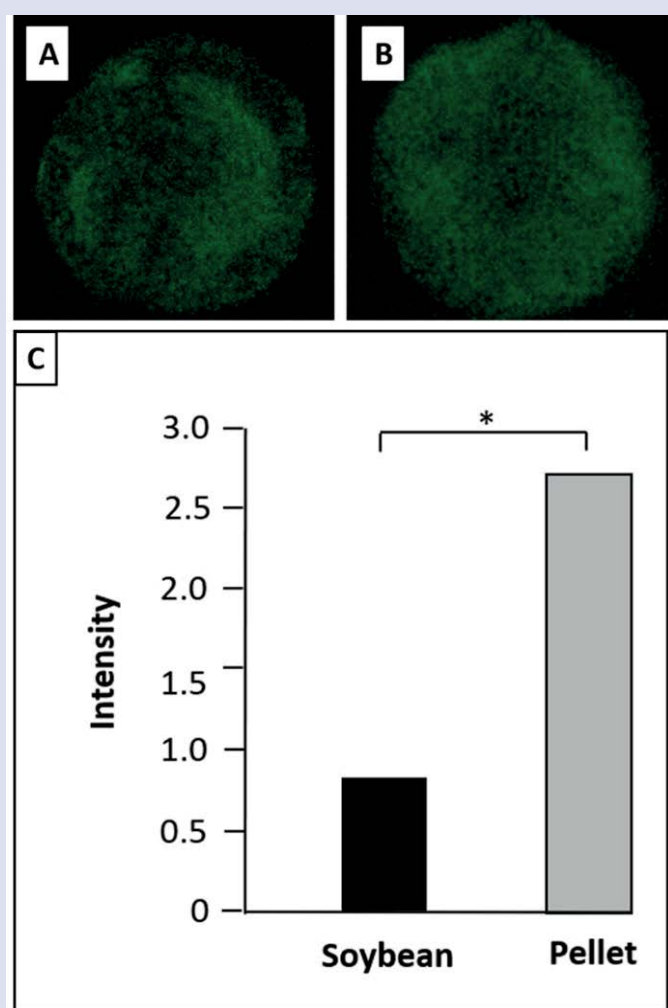

Figure 2: Oocytes apoptosis at (A) soybean-fed group, (B) pellet-only group, (C) intensity of oocyte apoptosis in both groups (dark colour = soybean group and grey colour = pellet group). 

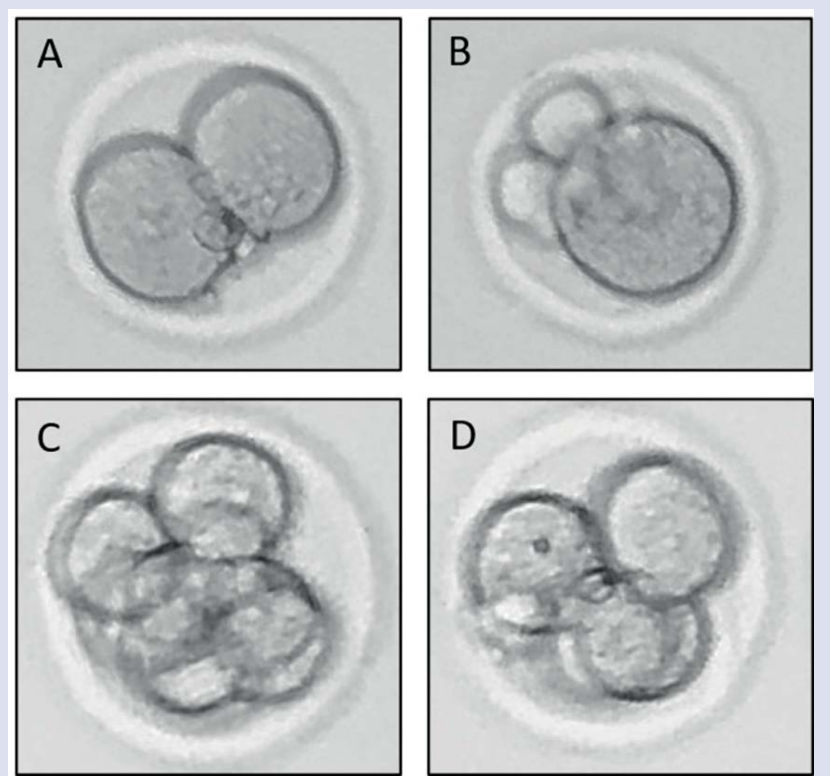

Figure 3: Embryo development on Day-1: A) good quality, B) poor quality and Day-3: C) good quality, D) poor quality.

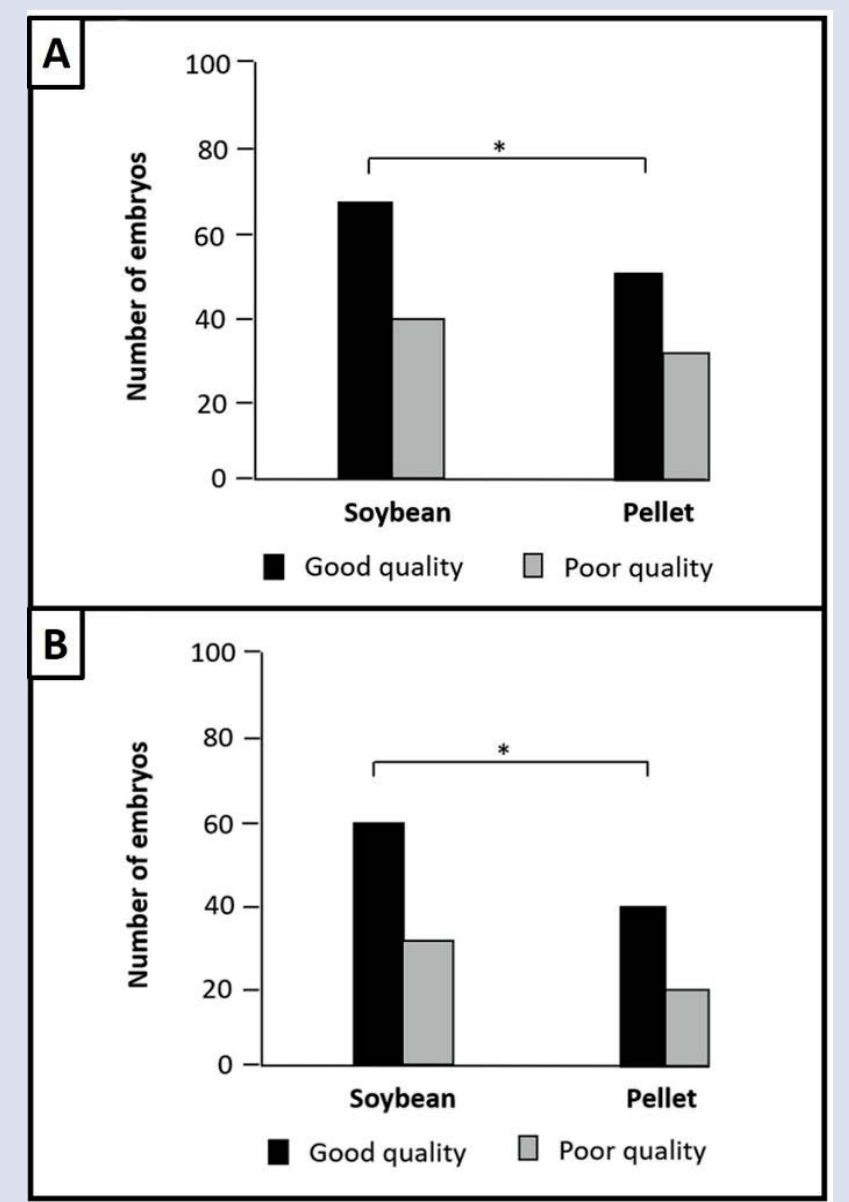

Figure 4: Comparison of embryo quality between groups on A) Day-1 and B) Day-3.

\section{The effect of soybean supplementation on oocyte viability}

The nutrition obtained by the mother can act directly on the hypothalamus-pituitary-ovarian axis, which can have an influence to the efficiency of the reproductive system, such as hormone synthesis, follicle growth and oocyte quality. ${ }^{16}$ According to research by Iguma et al. female mice that were given nutrients that contain high energy such as soybeans will affect the quality of viable oocytes. The treatment of soybean feed on female mice produced oocytes that had a better level of maturity and viability compared to untreated mice. This finding is line with the literature which states that oocytes maturity can be influenced by the presence of linoleic acid and genistein in soybeans. ${ }^{6}$

In terms of morphology, polar bodies, clear cytoplasm, clear periviteline zones, and perfect shape of zona pellucida, can be seen in a good shape from the oocytes treated by soybeans. However, oocyte with abnormal morphology can also be found, which is characterized by changes of the cell membrane and the loss of polar bodies. The underlying mechanisms may include several possibilities, such as unknown genetic disorders in mice, different ovarian response to hormone hyperstimulation, and changes in the microenvironment. ${ }^{17}$ Based on research conducted by Engelman et al. soybean supplementation can reduce the level of oxidative stress on oocyte development, although it doesn't have a significant effect. ${ }^{18}$

A higher average of MitoTracker fluorescence intensity in the SG could be explained by several nutrients contained in a soybean seed. Linoleic acid as a PUFA is known to have protective capabilities against cellular damages caused by saturated fatty acids. ${ }^{19,20}$ Simoes-Alves et al. observed that mitochondrial damage may arise from saturated fatty acids, which is shown by mitochondrial swelling due to compromise of normal membrane permeability. ${ }^{21}$ Mitochondrial damage as a result of saturated fatty acids also takes the form of increased ROS production and decreased respiration rate. Another nutrient, genistein, is also known to have positive effects on the cell and mitochondria. Genistein, a part from acting as an antioxidant, is also known to increase mitochondrial biogenesis by stimulating the expression of mitochondrial proteins and PGC-1 $\alpha^{22,23}$ Another nutrient of interest that plays a role in mitochondrial function is folic acid, which is known to help protect against ROS damage and homocysteine which is known to exhibit inhibitory properties to mitochondria through the inhibition of complex I - III. ${ }^{24,25}$

\section{The effect of soybean supplementation on oocytes apoptosis}

Apoptosis is a programmed cell death and can be caused by many factors and can be triggered by both physiological and pathological conditions. Various factors that can cause oocyte apoptosis are an increased oxidants, decreased meiotic competence, oocyte aging, presence of proapoptotic factors such as Bax and Caspase 9 protein, decreased signaling molecules, increased premature gap junction disorders, and increased apoptotic factors such as Caspase $3 .^{26,27}$ TUNEL stain can detect DNA fragmentation which is one of the causes of apoptosis. High intensity value indicates a higher level of apoptosis, whereas low intensity value indicates a lower level of apoptosis.

In this study, the mean value of oocyte apoptosis group given SG was lower significantly compared to PG. This may be influenced by the content of compounds in soybeans which can protect against oocytes. One of the compounds that acts as a protective oocytes is linoleic acid. Linoleic acid is an essential unsaturated fatty acid found in vegetable oils. Experiment by Nehra et al. stated that linoleic acid supplementation 
increases the reproductive function of mice, reduces ovarian aging and improves the quality of oocytes in advanced maternal age. ${ }^{28}$ In addition, linoleic acid also plays role in the expression of proapoptotic proteins such as Bcl-2 and Bax in oocytes, thereby affecting the apoptosis level of oocytes. ${ }^{17}$ Another study by Stinshoff et al. proved that there was a decrease in cell death in embryos cultured with $50 \mu \mathrm{M}$ conjugated linoleic acid compared to embryos cultured with control media. This is due to the function of linoleic acid which can disrupt cell membranes. ${ }^{6,29}$

In addition, linoleic acid which is a form of omega 3 fatty acids, also shows an easier conversion to fatty acids with other forms such as DHA, making it easier for the potential for these fatty acids to be mobilized from cells to oocytes. Linoleic acid is also more easily converted to arachidonic acid. Adequate concentration of arachidonic acid can stimulate oocyte maturation. Linoleic acid is a precursor of arachidonic acid through the atur-6 desaturase enzyme pathway. Nevertheless, arachidonic acid levels that are too high may have harmful effects on the body. ${ }^{30}$

Another substance in soybeans that can affect oocyte viability is content of genistein. Genistein is a bioactive molecule that exhibits the characteristics of an estrogen receptor modulator so that it impacts on potential effects at the cellular and molecular level of cells. In a study conducted by Chan et al. genistein has been shown to have a negative impact in the form of decreased oocyte maturation and injury to embryo developmental. This is because the research uses genistein in its purified form. However, the results of other studies show that the amount of genistein circulating in the circulation is very small when given in the form of soy. ${ }^{9,31}$

The effect of soybean supplementation on embryo development

Evaluation of embryo development after ICSI was performed repeatedly using an inverted microscope. Evaluation includes observations of cytoplasm, cell division, and zona pellucida. Based on observations, the early development of embryos (Day-1) from the treatment group showed better morphology of cell division (good embryo) compared to treatment without soybean (Figures $3 \mathrm{~A}$ and $4 \mathrm{~A}$ ). The early development of embryo from the SG had better results probably due to the linoleic acid content in soybeans which could affect the integrity of cell membrane during the cleavage state, and further influence the turgor pressure on the cell membranes.

From the description of early development of embryos (Day-1) without soybean supplementation, it can be seen that embryos show less cell division and more fragmentation (Figure $3 \mathrm{~B}$ and $4 \mathrm{~A}$ ). This can be caused by oxidative stress, which has the capacity to decrease the level of cell cycle factors such as embryo maturation factors, induce mitochondrial dysfunction, and directly damage embryo's intra cellular components such as lipid, protein, and DNA. ${ }^{32}$

Moreover, in further embryo development (Day-3), a similar pattern to Day-1 was obtained, namely the SG showed significantly more embryos with good quality compared to PG (Figure 4B).

Embryo viability can be influenced by several factors, such as water content, genetic traits, nutrition, and the environment. ${ }^{3}$ Based on the results, the embryos from SG showed better viability compared to embryos from PG. This was presumably due to oocytes obtained from mice treated with soybean has a better viability and morphology. ${ }^{33}$

Other finding of this study indicate that the number of embryos on Day-3 has decreased compared to Day-1 (Figures 4A and 4B). This is known as embryo blockage. The factors causing embryo blockage include contamination, heat stress, oxidative stress, and oocyte disruption or abnormalities at the embryo development stage. ${ }^{34}$ In this study, direct coating of liquid paraffin oil in the embryo culture medium may increase the risk of contamination, although this coating serves to reduce the level of damage to the culture media. ${ }^{15}$ In addition, possible contamination that may occur in the embryo can be caused by using the incubator together with other culture media. Another factor that causes embryo blockage is oocyte quality. ${ }^{33}$ In the ICSI procedure, the working time of each stage of the process is very important. The oocyte denudation process must be performed at regular temperatures and gases to minimize the pressure on the oocytes, so that the obtained oocytes have a low risk of damage. ${ }^{33}$ In this study, the oocyte denudation process takes place in a room with temperature control but without gas control, resulting in oocytes that are not fresh. Furthermore, the embryo may experience heat stress when placed in a portable incubator since it has a temperature higher than body temperature (above $37^{\circ} \mathrm{C}$ ). Based on research conducted by Nonogaki et al. too much polyunsaturated fatty acids (PUFAs) can inhibit embryonic development. This is because fatty acids can increase lipid metabolism and thus inhibit cell proliferation. ${ }^{34}$ In addition, according to research conducted by Bonacasa et al. high genistein concentrations $(10-15 \mu \mathrm{M})$ can inhibit cell compaction and embryonic division in 4-16 cell stages. This due to the inhibition of tyrosine phosphorylation of the cadherincatenin complex. Moreover, genistein is also known to cause cell cycle arrest in embryo division due to its inhibiting effect to tyrosine kinase. ${ }^{3.5}$

\section{CONCLUSION}

In conclusion, soybean supplementation improved embryo quality at the cleavage stage by decreasing apoptosis of the oocytes rather than increasing the viability of the oocytes.

\section{ACKNOWLEDGEMENT}

The authors would like to express gratitude to the "Hibah Publikasi Terindeks Internasional (PUTI) 2020" with contract number of NKB(1839)/UN2.RST/HKP.05.00/2020 from Universitas Indonesia for supporting this study.

\section{CONFLICTS OF INTEREST}

The authors declare no conflicts of interest.

\section{REFERENCES}

1. Mascarenhas MN, Flaxman SR, Boerma T, Vanderpoel S, Stevens GA. National, regional, and global trends in infertility prevalence since 1990: a systematic analysis of 277 health surveys. PLoS medicine. 2012;9(12):e1001356.

2. Audibert C, Glass D. A global perspective on assisted reproductive technology fertility treatment: an 8-country fertility specialist survey. Reproductive biology and endocrinology : RB\&E. 2015;13:133.

3. Ashworth CJ, Toma LM, Hunter MG. Nutritional effects on oocyte and embryo development in mammals: implications for reproductive efficiency and environmental sustainability. Philosophical transactions of the Royal Society of London Series B, Biological sciences. 2009;364(1534):3351-61.

4. Khalil WA, Marei WF, Khalid M. Protective effects of antioxidants on linoleic acid-treated bovine oocytes during maturation and subsequent embryo development. Theriogenology. 2013;80(2):161-8.

5. Marei WF, Wathes DC, Fouladi-Nashta AA. Impact of linoleic acid on bovine oocyte maturation and embryo development. Reproduction (Cambridge, England). 2010;139(6):979-88.

6. Amini E, Asadpour R, Roshangar L, Jafari-Joozani R. Effect of linoleic acid supplementation on in vitro maturation, embryo development and apoptotic related gene expression in ovine. International journal of reproductive biomedicine. 2016;14(4):255-62.

7. Ciepiela P, Bączkowski T, Drozd A, Kazienko A, Stachowska E, Kurzawa R. Arachidonic and linoleic acid derivatives impact oocyte ICSI fertilization--a prospective analysis of follicular fluid and a matched oocyte in a 'one follicle--one retrieved oocyte--one resulting embryo' investigational setting. PloS one. 2015;10(3):e0119087. 
8. Wei JH, Yuan XY, Zhang JM, Wei JQ. Caspase activity and oxidative stress of granulosa cells are associated with the viability and developmental potential of vitrified immature oocytes. European journal of obstetrics, gynecology, and reproductive biology. 2016;198:22-6

9. Chan WH. Impact of genistein on maturation of mouse oocytes, fertilization, and fetal development. Reproductive toxicology (Elmsford, NY). 2009;28(1):52-8.

10. Bagkos G, Koufopoulos K, Piperi C. A new model for mitochondrial membrane potential production and storage. Medical hypotheses. 2014;83(2):175-81.

11. Chazotte B. Labeling mitochondria with MitoTracker dyes. Cold Spring Harbor protocols. 2011;8:990-2.

12. Sorvina A, Bader CA, Darby JRT, Lock MC, Soo JY, Johnson IRD, et al. Mitochondrial imaging in live or fixed tissues using a luminescent iridium complex. Scientific reports. 2018;8(1):8191.

13. Hartshorne GM, Lyrakou S, Hamoda H, Oloto E, Ghafari F. Oogenesis and cell death in human prenatal ovaries: what are the criteria for oocyte selection? Molecular human reproduction. 2009;15(12):805-19.

14. Gardner DK, Balaban B. Assessment of human embryo development using morphological criteria in an era of time-lapse, algorithms and 'OMICS': is looking good still important? Molecular human reproduction. 2016;22(10):704-18

15. Rienzi L, Romano S, Albricci L, Maggiulli R, Capalbo A, Baroni E, et al. Embryo development of fresh 'versus' vitrified metaphase II oocytes after ICSI: a prospective randomized sibling-oocyte study. Human reproduction (Oxford, England). 2010;25(1):66-73.

16. Sales JN, Iguma LT, Batista RI, Quintão CC, Gama MA, Freitas C, et al. Effects of a high-energy diet on oocyte quality and in vitro embryo production in Bos indicus and Bos taurus cows. Journal of dairy science. 2015;98(5):3086-99.

17. Qassem E, Falah K, Aghaways I, Salih T. A correlative study of oocytes morphology with fertilization, cleavage, embryo quality and implantation rates after intra cytoplasmic sperm injection. Acta Medica International. 2015;2(1):7-13.

18. Engelman HM, Alekel DL, Hanson LN, Kanthasamy AG, Reddy MB. Blood lipid and oxidative stress responses to soy protein with isoflavones and phytic acid in postmenopausal women. The American journal of clinical nutrition. 2005;81(3):590-6.

19. Dunning KR, Russell DL, Robker RL. Lipids and oocyte developmental competence: the role of fatty acids and $\beta$-oxidation. Reproduction (Cambridge, England). 2014;148(1):R15-27.

20. Gehrmann W, Würdemann W, Plötz T, Jörns A, Lenzen $S$, Elsner M. Antagonism between saturated and unsaturated fatty acids in ros mediated lipotoxicity in rat insulin-producing cells. Cellular physiology and biochemistry : international journal of experimental cellular physiology, biochemistry, and pharmacology. 2015;36(3):852-65.
21. Simões-Alves AC, Costa-Silva JH, Barros-Junior IB, da Silva Filho RC Vasconcelos DAA, Vidal $H$, et al. Saturated fatty acid-enriched dietimpaired mitochondrial bioenergetics in liver from undernourished rats during critical periods of development. Cells. 2019;8(4).

22. Bailey AP, Koster G, Guillermier C, Hirst EM, MacRae JI, Lechene CP, et al. Antioxidant Role for Lipid Droplets in a Stem Cell Niche of Drosophila. Cell. 2015;163(2):340-53.

23. de Oliveira MR. Evidence for genistein as a mitochondriotropic molecule. Mitochondrion. 2016;29:35-44

24. Bhattacharjee A, Prasad SK, Banerjee O, Singh S, Banerjee A, Bose $A$, et al. Targeting mitochondria with folic acid and vitamin $B(12)$ ameliorates nicotine mediated islet cell dysfunction. Environmental toxicology. 2018;33(9):988-1000.

25. Chen S, Dong Z, Zhao Y, Sai N, Wang X, Liu H, et al. Homocysteine induces mitochondrial dysfunction involving the crosstalk between oxidative stress and mitochondrial PSTAT3 in rat ischemic brain. Scientific reports. 2017;7(1):6932.

26. Elmore S. Apoptosis: a review of programmed cell death Toxicologic pathology. 2007;35(4):495-516.

27. Tiwari M, Prasad S, Tripathi A, Pandey AN, Ali I, Singh AK, et al Apoptosis in mammalian oocytes: a review. Apoptosis : an international journal on programmed cell death. 2015;20(8):1019-25.

28. Nehra D, Le HD, Fallon EM, Carlson SJ, Woods D, White YA, et al. Prolonging the female reproductive lifespan and improving egg quality with dietary omega-3 fatty acids. Aging cell. 2012;11(6):1046-54.

29. Stinshoff $\mathrm{H}$, Wilkening $\mathrm{S}$, Hanstedt A, Bollwein $\mathrm{H}$, Wrenzycki $\mathrm{C}$. Dimethylsulfoxide and conjugated linoleic acids affect bovine embryo development in vitro. Reproduction, fertility, and development. 2014;26(4):502-10.

30. Hilbig CC, Nascimento NFd, Heinen AL, Tovo Neto A, Funghetto $\mathrm{JP}$, Bombardelli RA, et al. Effects of dietary fatty acids on the reproduction of South American female catfish Rhamdia quelen (Quoy \& Gaimard, 1824). Latin american journal of aquatic research. 2019;47:456-66.

31. Setchell KD. Assessing risks and benefits of genistein and soy. Environmental health perspectives. 2006;114(6):A332-3.

32. Lord T, Aitken RJ. Oxidative stress and ageing of the post-ovulatory oocyte. Reproduction (Cambridge, England). 2013;146(6):R217-27.

33. Rienzi L, Vajta G, Ubaldi F. Predictive value of oocyte morphology in human IVF: a systematic review of the literature. Human reproduction update. 2011;17(1):34-45.

34. Nonogaki T, Noda $Y$, Goto $Y$, Kishi J, Mori T. Developmental blockage of mouse embryos caused by fatty acids. Journal of assisted reproduction and genetics. 1994;11(9):482-8.

35. Bonacasa B, Siow RC, Mann GE. Impact of dietary soy isoflavones in pregnancy on fetal programming of endothelial function in offspring. Microcirculation (New York, NY : 1994). 2011;18(4):270-85. 


\section{GRAPHICAL ABSTRACT}

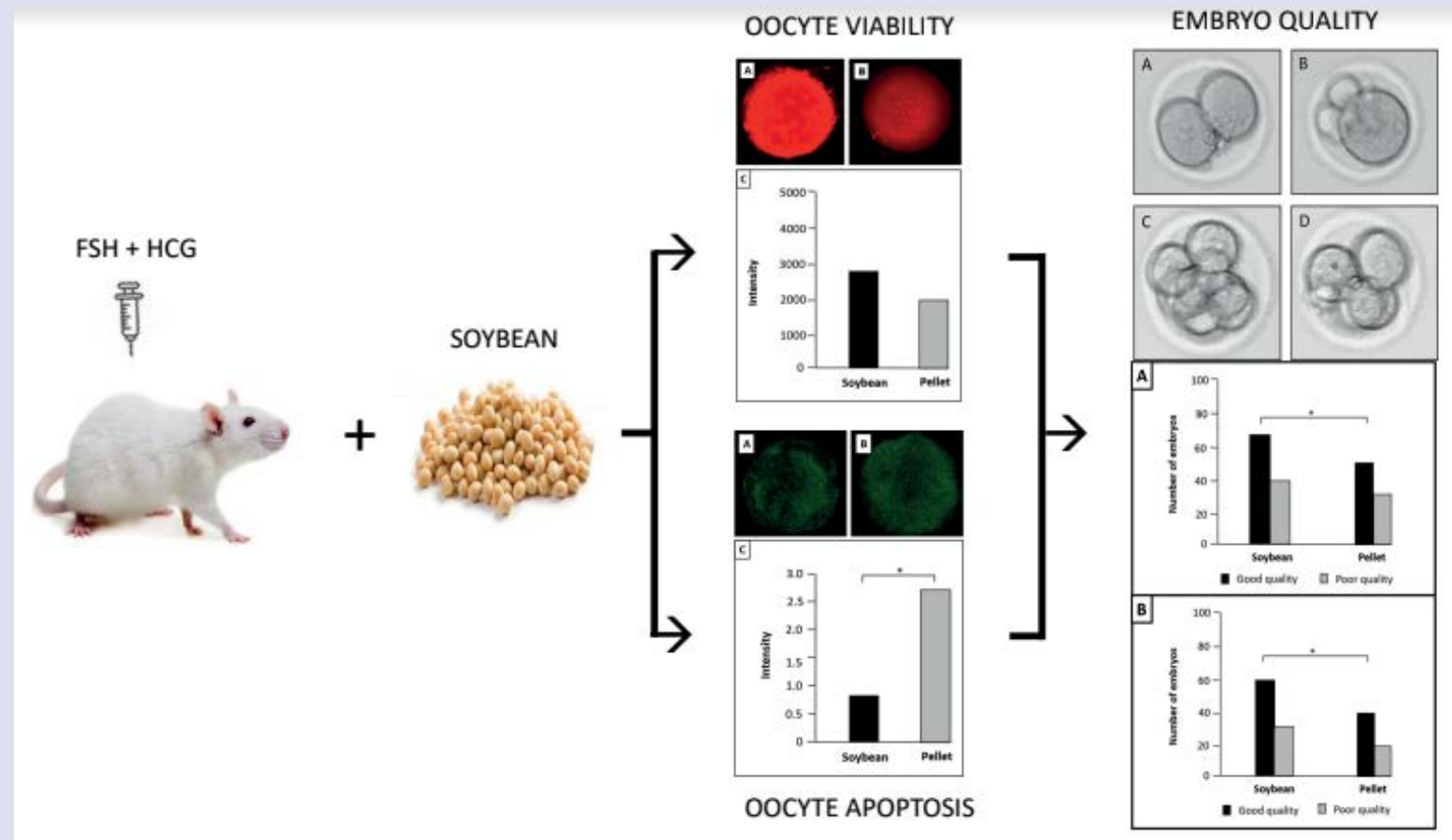

\section{ABOUT AUTHORS}
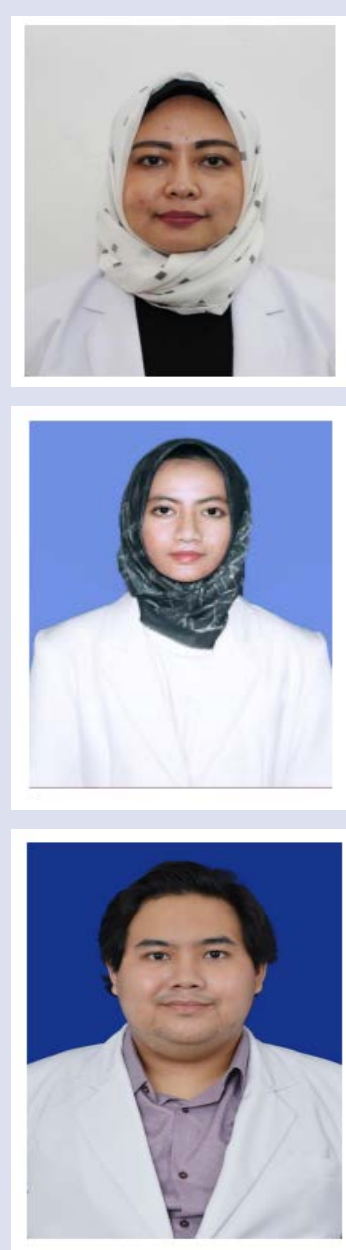

Silvia werdhy lestari is a senior clinical staff at Department of Medical Biology Faculty of Medicine Universitas Indonesia, andrologist, embriologist, scientist, and lecturer. She received her Master and Doctor of Biomedical Science from Universitas Indonesia. Her research started in 2013 until 2021 focus on reproductive health, male fertility, sperm, oocyte, embryo, clinical embriology and stem cell.

Khairunnisa Farina llato is a medical student who currently doing her clinical clerkship at Faculty of Medicine, Universitas Indonesia. She has strong passion in scientific research and biostatistics. She has been involved in several related researches about embryology. She also involved in several organizations and international competitions.

Muhammad lqbal Adi Pratama is a medical student in Faculty of Medicine Universitas Indonesia. He had acquired research experience in embryology where he is involved in two related researches. He also had research experience in synthetic biology where he is involved in a research competition and join authored a collaborative research paper. 

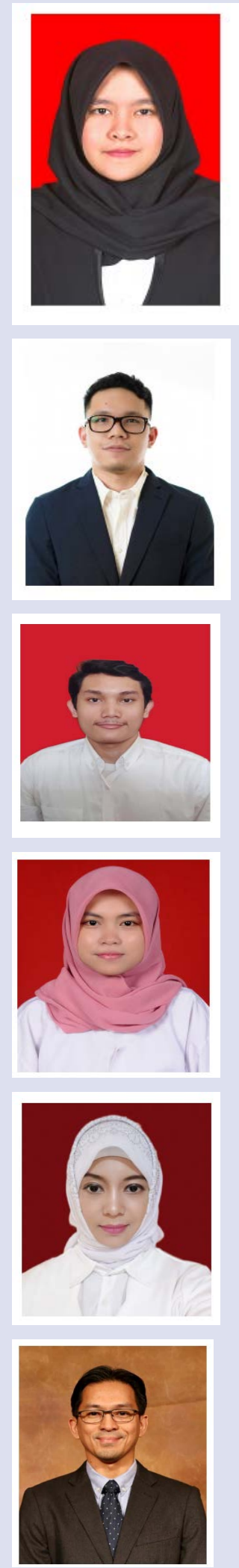

Husna Qonita is a researcher from Universitas Indonesia. She received science degree from biology department Universitas Indonesia. She has been involved in research on reproductive medicine especially IVF-ICSI.

Gito Wasian is junior staff at Department of Medical Biology, Faculty of Medicine, University of Indonesia. He obtained medical degree from University of Indonesia and completed andrology residency program at Airlangga University. He took basic embryology training in Surabaya. He specializes in andrology and is particularly interested in assisted reproductive technology.

Amandanu Bramantya is a medical student in the Faculty of Medicine Universitas Indonesia. He is currently doing research under the Department of Biology, Faculty of Medicine Universitas Indonesia for his undergraduate program. His current research and field of interests include reproductive health and assisted reproductive technology.

Firda Asma'ul Husna is a researcher in Faculty of Medicine Universitas Indonesia (FMUI). She received master degree from Master's Programme in Biomedical Sciences FMUI. She worked carefully in the laboratory of culture, embryology and immunopathology. She has been involved in research on stem cells and IVF (IVFICSI). She Able to work together in a team that has the same vision and mission.

Ria Margiana is a senior clinical staff at Department of Anatomy, reasearcher, and lecturer in Anatomy Concentration Courses, Master's Programe in Biomedical Sciences Faculty of Medicine, Universitas Indonesia. She received her Master and Doctor of Biomedical Science from Universitas Indonesia. Her research started in 2015 until 2021 focus on reproductive health, embryo development, infertility, sperm, and stem cell.

Gita Pratama is a gynecologist, senior clinical staff, scientist and lecturer in the Department of Obstetrics and Gynecology, Faculty of Medicine Universitas Indonesia. He received his Master of Reproductive Sciences degree from Monash University, Australia. His research and teaching activities focus on reproductive health, reproductive endocrinology and stem cells.

Cite this article: Lestari SW, Ilato KF, Pratama MIA, Qonitah H, Wasian G, Bramantya A, et al. Does Soybean (Glycine max) Supplementation Increase Oocyte Viability, Decrease Oocyte Apoptosis and Improve Embryo Development Quality? An Experimental Study. Pharmacogn J. 2022;14(1): 133-140. 